\title{
Thermo-oxidative stabilization of polylactic acid-based nanocomposites through the incorporation of clay with in-built antioxidant activity
}

Nadka Tzankova Dintcheva ${ }^{* 1,2}$, Sahar Al-Malaika ${ }^{2}$, Elisabetta Morici ${ }^{1}$, Rossella Arrigo ${ }^{1}$

${ }^{1}$ Dipartimento di Ingegneria Civile, Ambientale, Aerospaziale, dei Materiali, Università di Palermo, Viale delle Scienze, Ed. 6, 90128 Palermo, Italy

${ }^{2}$ Polymer Processing and Performance Research Unit, School of Engineering and Applied Science, Aston University, Aston Triangle, Birmingham, B4 7ET, UK

Correspondence to: Nadka Tzankova Dintcheva (E-mail: nadka.dintcheva@unipa.it)

\begin{abstract}
In this work, an innovative approach to overcome the issue of the poor thermo-oxidative stability of polymer/clay nanocomposites is proposed. Specifically, biodegradable polylactic acid (PLA)-based nanocomposites, containing organo-modified clay with in-built antioxidant activity, were prepared. Through a two-step chemical protocol, a hindered phenol antioxidant was chemically linked to the ammonium quaternary salt which was then intercalated between the clay platelets ((AO)OM-Mt). The nanocomposites were characterized and their thermo-oxidative stability during melt processing and under long-term thermal test conditions was investigated.

PLA nanocomposites containing the (AO)OM-Mt showed higher oxidative stability, along with better clay dispersion, compared to PLA-nanocomposites containing commercial clay and a free hindered phenol antioxidant. Obtained results can be explained considering that (AO)OM-Mt may act locally, at the interface, between the silicate layers and the polymer macromolecules, thus contributing to the observed improved stability of the polymer both during processing and under long-term thermaloxidative conditions.
\end{abstract}




\section{INTRODUCTION}

Biopolymers are compostable environmentally friendly non-fossil based materials. ${ }^{1,2}$ Polylactic acid (PLA), a low toxicity biocompatible biopolymer, has seen an increasing commercial interest in many applications including food packaging, textile fibers, drug delivery, biomedical applications and agriculture. ${ }^{3,4}$ Processing of PLA at elevated temperatures affects adversely its mechanical and thermomechanical resistance and gas barrier properties. ${ }^{5}$ Organo-modified layered silicate clays have been used to address the issues of its thermo-mechanical stability and gas barrier properties. ${ }^{6-9}$ The adding of clay also affect the thermal stability of PLA; generally, the presence of clay leads to an increase of the PLA thermal stability, attributable to a rearrangement of silicate layers on the nanocomposite surface, creating a protective barrier. ${ }^{10-12}$ In some cases, the thermal stability of PLA is worsened by the presence of the clays. ${ }^{13-15}$ For instance, Wu et al. ${ }^{15}$ reports a linear decrease of the decomposition temperature of PLA-based nanocomposites as a function of the clay content. Although it is still not clear the mechanism that causes this behaviour, the authors stated that clays are able to act as deformation accelerators at higher temperatures.

The significant property improvement observed in clay-containing polymer nanocomposites has been attributed mainly to interfacial interactions between the polymer matrix and the nanoparticles. ${ }^{16-18}$ However, the presence of organically-modified clay in polymeric matrices has been shown to enhance the rate of thermo- and photo- oxidative degradation of the polymer nanocomposite products. ${ }^{19-21}$ The adverse effects brought about by these nanofillers is due to a combination of factors including the catalytic effect of impurities in the clay, adsorption of the stabilisers on the clay surface which reduces their effectiveness, and the intrinsic thermal degradation of the ammonium organo-modifiers. Further, the use of conventional stabilising systems in clay-polymer nanocomposites have not been satisfactory due to their consumption, loss or migration during processing and in-service, or due to their adsorption on the nanofiller surfaces. ${ }^{22-25}$ In the case of PLA-nanocomposites, although the incorporation of clay 
improves a number of its properties, its thermal oxidative stability was shown to be adversely affected resulting in random chain scission leading to a reduction in the molecular mass of the polymer. ${ }^{26-28}$ This work reports on the stabilisation of organo-modified montmorillonite clay - PLA nanocomposites. The organo-modified clay was intrinsically stabilised by bonding it covalently to an antioxidant function denoted here as (AO)OM. The morphology of the nanocomposite samples was characterised by scanning and transmission electron microscopy, SEM and TEM, respectively, and by X-Ray diffraction. The thermo-oxidative stability of the PLA/(AO)OM-Mt nanocomposites was assessed by infrared spectroscopy, rheological analysis and differential scanning calorimetry (DSC), and compared to that of the PLA and PLA-nanocomposites containing commercial modified clay (PLA/OM-Mt) in the presence and absence of free commercial hindered phenol antioxidant which was added during melt processing of the clay-polymer nanocomposite.

\section{EXPERIMENTAL}

\section{Materials}

The polylactic acid (PLA) used was PLA 2002D, a commercial extrusion sheet grade supplied by NatureWorks (Nebraska, USA) with average number molecular weight about $121000 \mathrm{~g} / \mathrm{mol}$, ratio $96 \%$ Llactide to $4 \%$ D-lactide units, melt flow index $6 \mathrm{~g} / 10 \mathrm{~min}\left(230^{\circ} \mathrm{C}, 2.16 \mathrm{Kg}\right)$. Prior to processing, PLA pellets were dried at $70^{\circ} \mathrm{C}$ under vacuum.

The commercially available nanoclays used in this work were:

- Cloisite ${ }^{\circledR} \mathrm{Na}+$, (Mt), a natural unmodified montmorillonite supplied by Southern Clay Products (Texas, USA) with ionic exchange capacity $92.6 \mathrm{meq} / 100 \mathrm{~g}$, specific gravity $2.86 \mathrm{~g} / \mathrm{cm} 3$ and d001=1.18nm (XRD peak $2 \theta=7.50 \mathrm{deg})$.

- Cloisite ${ }^{\circledR} 30 \mathrm{~B}$, an organically modified montmorillonite (OM-Mt) supplied by Southern Clay Products (Texas, USA) with ionic exchange capacity $90 \mathrm{meq} / 100 \mathrm{~g}$, specific gravity $1.98 \mathrm{~g} / \mathrm{cm} 3$ and d001=1.85 nm. 
The organic modifier intercalated between the platelets of the clay is a bis-(2-hydroxyethyl) methyl tallow alkyl ammonium cation.

The antioxidant-organo-modified clay ((AO)OM-Mt) was produced (see below) by cation-exchange reaction between the commercial natural unmodified $\mathrm{Mt}$ and an ammonium salt of the antioxidantcontaining organic modifier, named here $(\mathrm{AO}) \mathrm{OM}$, synthesized according to procedure reported earlier. ${ }^{29}$ Briefly, to produce (AO)OM, a reactive antioxidant molecule (a hindered phenol) was grafted onto a quaternary ammonium salt (2-hydroxyethyl)oleylmethylbis ammonium chloride, molecular weight of $370.64 \mathrm{~g} / \mathrm{mol}$ and formula: $\mathrm{C}_{23} \mathrm{H}_{48} \mathrm{NO}_{2}$, supplied by Akzo Nobel ${ }^{\circledR}$ under the trade name ETHOQUAD $^{\circledR} \mathrm{O} / 12$ PG This ammonium salt which was used to produce the (AO)OM product is the same as that present in the commercial Cloisite ${ }^{\circledR 30 B}$. As was shown previously, ${ }^{29}$ the (AO)OM is a mixture of mono- and di- substituted compounds containing one and two Irganox acid molecules, respectively, at a ratio of approximately 2:3.

A sterically hindered phenol antioxidant Irganox ${ }^{\circledR} 1076$ (Octadecyl-3-(3,5-di-tert-butyl-4-hydroxyphenyl)propionate) is an ex. Ciba ${ }^{\circledR}$ Specialty Chemicals (BASF, Italy) (MW=531 g/mol).

\section{Preparation of (AO)OM-Mt}

The (AO)OM was intercalated by a cation-exchange reaction with the commercial unmodified montmorillonite clay (Mt), see Fig. 1. In particular, more than twice the exchange capacity of the host clay was dissolved in a mixture of ethanol and deionised water at ratio of 3:1. After sonication and stirring $\left(60 \mathrm{~min}\right.$ at $90^{\circ} \mathrm{C}$ ), the solution was added to a $2 \mathrm{wt} . \%$ aqueous suspension (deionised water : ethanol $=1: 1$ ) of the natural sodium layered silicate clay $(\mathrm{Mt})$ andstirred for a further $5 \mathrm{~h}$ at $90^{\circ} \mathrm{C}$. The product was recovered after filtration and subsequent washing with a mixture of hot ethanol and deionised water until an $\mathrm{AgNO}_{3}$ test indicated the absence of chloride anions. The cation-exchanged silicates was dried at room temperature, pulverized, and further dried at $80^{\circ} \mathrm{C}$ under vacuum for at least $24 \mathrm{~h}$. 


\section{Preparation of PLA-based nanocomposites}

PLA based nanocomposites were formulated by melt mixing using a Haake Minilab Rheomex microcompounder model CTW5 conical twin -screw extruder operating in a co-rotating mode. The processing temperature was $170^{\circ} \mathrm{C}$, the residence time 5 minutes and the rotation speed was $100 \mathrm{rpm}$. All the nanofillers (Mt, OM-MT and (AO)OM-Mt) were added at 5\% w/w, to the polymer melt after 2 minutes of processing. Neat PLA was subjected to the same processing condition. For comparison, a different formulation was made by adding a mixture of OM-Mt (5 wt.\%) and free antioxidant (Irganox 1076) molecules (1 wt.\%) to the polymer, to obtain (PLA/OM-Mt/AO).

\section{Characterisation}

Fourier Transform Infrared Spectrometer, FTIR (Spectrum One, Perkin Elmer), was used to record IR spectra using 16 scans at a resolution of $4 \mathrm{~cm}-1$. FTIR analysis was carried out on pressed KBR pellets containing clay (at $4 \% \mathrm{w} / \mathrm{w}$ ) and on films of neat PLA and its nanocomposites. Measurements were made on three separately prepared batches of samples. Surface IR analyses of the PLA films were carried out using ATR accessory fitted with a diamond crystal.

Diffraction spectra of the clay samples were obtained using a Wide Angle X-ray Diffraction (WAXD) Siemens D-500 in reflection mode, with filtered Cu-K $\alpha$ radiation, wavelength $\lambda=0.1542 \mathrm{~nm}$ and a scan rate of $1.0 \mathrm{deg} / \mathrm{min}$ over the diffraction angle $(2 \theta)$ ranging from $2^{\circ}$ to $15^{\circ}$. The interlayer distance, $\mathrm{d}$, was determined according to the Bragg's formula:

$\mathrm{n} \lambda=2 \mathrm{~d} \sin \theta$

where $\mathrm{n}$ is the diffraction order, $\lambda$ - wavelength, $\theta$ - incident angle.

Scanning (SEM) and transmission (TEM) electron microscopy were used to characterise the morphologies of both the polymeric matrix and nanocomposites. SEM analysis of the liquid nitrogen radially fractured (gold sputtered) surfaces were carried out on a Philips (Netherlands) ESEM XL30 microscope.TEM images of microtomed specimens were obtained using a JEOL JEM-2100 microscope 
under accelerated voltage of $200 \mathrm{kV}$; ultrathin films (thickness $100 \mathrm{~nm}$ ) were cut from specimens embedded in epoxy resin using a Leica Ultramicrotome EM-UC6.

The X-Ray Diffraction (XRD) analysis of PLA and PLA-based nanocomposites was performed using an Empyrean Series 2 X-Ray Diffraction (Panalytical): the spectra of the film samples were recorded in the range 3-30 deg (step size $=0.025$, scanning rate $=60 \mathrm{~s} / \mathrm{step}$ ) and $\mathrm{Cu}-\mathrm{K} \alpha$ radiation at wavelength $\lambda=0.1542$ $\mathrm{nm}$.

Rotational rheometry was applied to assess the rheological characteristics of PLA and its nanocomposites. A Rheometric Scientific (USA) RDA II parallel plate-plate (steel plates) rotational rheometer was run at $\mathrm{T}=170^{\circ} \mathrm{C}$ under a $5 \%$ strain deformation (this was chosen after performing amplitude sweeps at 0.1 and $100 \mathrm{rad} / \mathrm{sec}$ to ensure that the dynamic tests are carried out in the linear viscoelasticity region). The complex viscosity $\left(\eta^{*}\right)$ and the storage $\left(G^{\prime}\right)$ and loss $\left(G^{\prime \prime}\right)$ modulii were recorded as a function of frequency in the range $0.1-100 \mathrm{rad} / \mathrm{sec}$.

Differential scanning calorimetry (DSC) was performed using a Perkin-Elmer DSC7 calorimeter. All experiments were run under dry N2 with samples of about $10 \mathrm{mg}$ in $40 \mu \mathrm{l}$ sealed aluminium pans. Four calorimetric scans (heating scan: $30-185^{\circ} \mathrm{C}$; cooling scan: $185-30^{\circ} \mathrm{C}$ ) were performed for each sample at a heating rate of $10^{\circ} \mathrm{C} / \mathrm{min}$ and a cooling rate of $40^{\circ} \mathrm{C} / \mathrm{min}$.

The degree of crystallinity $\left(X_{c}\right)$ was calculated using the formula:

$X_{c}(\%)=\frac{\Delta H_{m}+\Delta H_{c c}}{\Delta H^{\circ}\left(1-W_{f}\right)} \times 100$

where, $\Delta H_{m}$ is the melting heat of the sample, $\Delta H_{c c}$ is the heat of cold crystallization, $\Delta H^{\circ}$ is the heat of fusion for a $100 \%$ crystalline PLA $(93 \mathrm{~J} / \mathrm{g})^{30}$ and $W_{f}$ is the mass fraction of the nanofiller.

The DSC analysis has been performed on three different samples and calculated standard deviation has been reported in Table 1 and Figure 12.

Thermo-oxidation of thin films (about $100 \mu \mathrm{m}$ ) was carried out in a forced-air circulation oven at $115^{\circ} \mathrm{C}$. The progress of degradation was followed both by spectroscopic (IR) and calorimetric (DSC) techniques. 


\section{RESULTS AND DISCUSSION}

\section{Characterization of (AO)OM-Mt}

Intercalation of the (AO)OM into the natural clay $(\mathrm{Mt})$ was probed by carrying out both $\mathrm{x}$-ray diffraction and FT-IR analyses. Fig. 2 shows the FTIR spectra of clays, deconvoluted spectra of OM-Mt and (AO)OMMt. The FTIR spectra of the OM-Mt and (AO)OM-Mt reveal similarities and differences when compared to the spectra of the natural Mt. The spectra of both organo-modified clays, in the frequency interval $3700-3200 \mathrm{~cm}^{-1}$, display the typical absorption signal of the unmodified clay. The absorption band centered at $3626 \mathrm{~cm}^{-1}$ is related to $-\mathrm{OH}$ stretching of the structural hydroxyl groups of the $\mathrm{Mt}$, while the absorption band centered at $3450 \mathrm{~cm}^{-1}$ is due to $\mathrm{H}-\mathrm{O}-\mathrm{H}$ vibrations of adsorbed water; furthermore, the interlayer water molecules of Mt show a bending mode of vibration which appears as a strong absorption with peak at $\left.1640 \mathrm{~cm}^{-1}\right) \cdot{ }^{31}$ However, the peak at $3450 \mathrm{~cm}^{-1}$ shifts to lower frequencies, in both OM-Mt and (AO)OM-Mt, due to the presence of -OH groups in the $\mathrm{OM}$ and those of the hindered phenols in (AO)OM, respectively. Moreover, the bands centered at $1640 \mathrm{~cm}^{-1}$ is significantly influenced by the radius, the valence charge and hydration energies of the exchanged cations: in the two organomodified clays, this peak appears to have lower intensity than that of Mt because of the lower amount of coordination water attached to the organo-modifier cations compared to the exchanged $\mathrm{Na}+$ cations. The presence of absorption bands in the range $3000-2800 \mathrm{~cm}^{-1}$ in the organo-modified clays spectra is attributed to the organic part of the organo-modified clays. A deconvolution of the IR spectra of the organo-modified clays in this range, show three absorption peaks centered at 2855, 2931 and $2965 \mathrm{~cm}^{-1}$ which correspond to the different $\mathrm{CH}$ stretching vibrations. The peak at $2965 \mathrm{~cm}^{-1}$, assigned to the $-\mathrm{CH}_{3}$ stretching vibration, is more resolved in the deconvoluted spectrum of the (AO)OM-Mt sample compared to that of OM-Mt because of a larger number of methyl groups in the (AO)OM-Mt which, contains six $\mathrm{CH}_{3}$ groups per each hindered phenol of the antioxidant molecules within its structure. 
The absorption peaks in the range between 1500 and $1420 \mathrm{~cm}^{-1}$ arise from the organo-modifier: $:^{32}$ peaks at 1485 and $1460 \mathrm{~cm}^{-1}$ are attributed to the bending vibrations of $-\mathrm{C}-\mathrm{C}$ - and $-\mathrm{C}-\mathrm{H}$ groups; the band at $1470 \mathrm{~cm}^{-1}$ is assigned to the bending of $-\mathrm{CH}_{2}$ groups overlapping the $\mathrm{C}-\mathrm{N}$ stretching vibration. ${ }^{32}$ The inplane bend vibration of the $-\mathrm{CH}_{3}$ - groups appears at $1437 \mathrm{~cm}^{-1}$ along with the additional absorption peak at $1738 \mathrm{~cm}^{-1}$ (corresponding to the stretching of ester groups $-\mathrm{O}-(\mathrm{C}=\mathrm{O})-$ ), are only noticeable in the (AO)OM-Mt spectrum, and are, therefore, attributable to the hindered phenol antioxidant molecules grafted onto the organo-modifier. In summary, the FT-IR spectra of (AO)OM-Mt show typical signals of the organo-modified clay; the differences between (AO)OM-Mt and OM-Mt spectra arise from the presence of the grafted antioxidant functionalities.

In Fig. 3, the XRD spectrum of (AO)OM-Mt is shown alongside that of OM-Mt. The calculated interlayer distance (through Bragg's relation) of commercial OM-Mt clay is $1.85 \mathrm{~nm}$ (main peak $2 \theta=4.76 \mathrm{deg}$ ), in accordance with the data on the manufacturer's datasheet. The modification of clay, as a result of the cation-exchange reaction, leads to a shift of the diffraction peak towards lower angles due to the increase in the inter-galleries spacing, attributed to the higher steric hindrance caused by the presence of (AO)OM moiety compared to that of the OM alone. The calculated interlayer distance of (AO)OM-Mt is $2.05 \mathrm{~nm}$ (main peak $2 \theta=4.30 \mathrm{deg}$ ), confirming the successful intercalation of $A O(O M)$ into the stacked layers of the Mt clay.

\section{Characterization of PLA-based nanocomposites}

XRD analysis is a useful tool to reveal clay intercalation and/or exfoliation in polymer-based nanocomposites. Fig. 4 shows the XRD intensity distributions recorded for unfilled PLA and its nanocomposites in the range 3-30 deg. PLA pattern is characterized by a broad intensity feature with a maximum at about $2 \theta=15 \mathrm{deg}$, which suggests the presence of an almost amorphous structure in this sample. In PLA/Mt a sharp peak appears at $2 \theta=7.5 \mathrm{deg}$ which is attributed to the presence of pristine Mt stacks. The PLA/OM-Mt nanocomposite shows a peak at $2 \theta=4.8 \mathrm{deg}$, attributed to the presence of 
OM-Mt stacks, and a peak at $2 \theta=7.5 \mathrm{deg}$, that is attributable to the presence of fraction of unmodified Mt stacks resulting from the pristine clay and/or from collapsed clay structure after the removal or degradation of the organo-modifier during processing at high temperatures. ${ }^{33}$ The conventional addition of the antioxidant (AO), at $1 \mathrm{wt} \%$, to PLA/OM-Mt system (sample PLA/OM-Mt/AO) does not significantly affect the intercalation/exfoliation of the clay, since the positions of the peaks remain unchanged. The (AO)OM-Mt characteristic peak at $2 \theta=4.3 \mathrm{deg}$ is observed in the PLA/(AO)OM-Mt spectrum, indicating the presence of some stacks of clay in the nanocomposite; furthermore a small shoulder at about $2 \theta=$ 6.3 deg is observed, attributable to the clay-stacks too.

Changes in the polymer morphology and the state of dispersion of the clay in nanocomposites following melt processing are better understood with the aid of SEM and TEM imaging. Fig. 5, shows SEM micrographs of the neat PLA matrix and its nanocomposites.

In the PLA/Mt micrograph, the presence of Mt aggregates is noticeable, suggesting a poor clay dispersion. Therefore, the interaction between the carbonyl and hydroxyl-end groups of PLA and the hydroxyl group in the surface of the clay, together with shear forces applied during melt processing, are not sufficient to affect clay delamination. By contrast, the PLA nanocomposites, containing both OMMt and (AO)OM-Mt, appear to be more homogeneous throughout pointing to an intercalatedexfoliated morphology, alongside some organo-clay tactoids. These features would suggest the positive effect of organo-modification in favouring interaction and intercalation between the polymer chains and the layered fillers. It is worth noting that the observed surface of nanocomposites containing the organo-modified clays appears rougher than that of the PLA due to the presence of the dispersed nanofiller. The surfaces of both the stabilised nanocomposites, and more so of the PLA/(AO)OM-Mt sample, appear much smoother than that of the unstabilised PLA/OM-Mt nanocomposite sample: this is construed to suggests the existence of an inherent advantage of the stabilising action of the antioxidant molecules in protecting the clay-polymer system during processing. 
The TEM images for PLA/OM-Mt and PLA/(AO)OM-Mt nanocomposites are shown in Fig.6. It can be seen clearly that both organo-clays are exfoliated and well dispersed in the nanocomposites. Moreover, it appears that PLA/(AO)OM-Mt nanocomposites show a smaller number of layers in each stack compared to that of the PLA/OM-Mt sample. It is suggested here that the larger interlayer distance between the silicate layers in (AO)OM-Mt, compared to that of the OM-Mt as assessed by XRD, aids further the process of intercalation of the polymer macromolecules.

Assessment of the rheological properties of PLA-based nanocomposites helps to evaluate the extent of change in the viscoelastic properties arising from polymer-filler interactions, as well as the effect of layered silicates on the degradation during processing. Fig. 7 (a-c) show the complex viscosity, $\eta^{*}$, the storage modulus, G', and the loss modulus, G", as function of frequency, $\omega$, for PLA and its nanocomposites. The complex viscosity of the neat matrix shows a Newtonian plateau at low to mid frequencies and a shear-thinning behaviour at the higher frequencies. The Newtonian plateau viscosity is observed also in the nanocomposite PLA/Mt sample. The presence of the organo-clay in filled PLA melts modifies the rheological behaviour with respect to that of the unfilled polymer, due to the formation of network structure in the PLA matrix. Indeed, in the low frequency range, the behaviour of the nanocomposites containing the different organo-clays is non-Newtonian and shows a pseudo-yieldstress behaviour: at higher shear rates the effect of the filler decreases and the matrix contributions dominate. In PLA/OM-Mt nanocomposite, this rheological behaviour is affected by the interactions between the carbonyl and the hydroxyl-end groups in the polymer chains and the hydroxyl groups of the organo-modifier that help both the intercalation of the polymer and the clay exfoliation, as has been reported previously. ${ }^{34-35}$ The rheological behaviour of PLA/OM-Mt/AO nanocomposite (i.e. containing the free $A O$ molecules), is similar to that observed for PLA/OM-Mt nanocomposite, although the viscosity curve is shifted toward higher values. This is to be expected since the free AO molecules are able to offer protection during processing, thereby preventing degradation and the reduction in the 
molar mass of polymer matrix. PLA/(AO)OM-Mt nanocomposite shows the highest viscosity values and most prominent non-Newtonian behaviour due to a stabilising effect of grafted $A O$ molecules by preventing the thermo-oxidative degradation during processing and improving the clay dispersion. In PLA/OM-Mt nanocomposite, the exfoliation achieved is related to the interaction between functional groups in PLA chains and the hydroxyl groups of OM, whereas, in PLA/(AO)OM-Mt nanocomposite, due to the fact that the hydroxyl groups of OM had been replaced by the AO functionalities, the clay exfoliation is thought to occur on account of the greater interlayer distance between the layers in (AO)OM-Mt with respect to that of the OM-Mt.

Plots of storage (G') and loss (G") moduli as function of $\omega$ are shown in Fig. 7 (b-c). The neat PLA exhibits a typical homo-polymer terminal behaviour, i.e. $G^{\prime} \alpha \omega^{2}$ and $G^{\prime} \alpha \omega$ at low frequencies, while the presence of clay causes a transition from liquid-like to solid-like in the PLA-based nanocomposites. Indeed, $G^{\prime}$ and $G^{\prime \prime}$ curves tend to be frequency independent in the low frequency region due to supramolecular structural formation in these nanocomposites. ${ }^{34}$ The analysis of both $G^{\prime}$ and $G^{\prime \prime}$ moduli trends for PLA/OM-Mt and PLA/OM-Mt/AO nanocomposites, confirms the strong interactions between the organo-modifier and PLA chains which play a significant role in the obtained exfoliated morphology. The presence of (AO)OM-Mt brings about the most significant alterations in the trends of the $\mathrm{G}^{\prime}$ and $\mathrm{G}^{\prime \prime}$ moduli with respect to the OM-Mt containing sample, confirming the higher extent of clay dispersion and exfoliation and that of the protective action afforred by the grafted AO molecules.

\section{Long-term thermo-oxidative stability of PLA-based nanocomposites}

The long-term thermo-oxidative stability of the neat PLA and PLA-based nanocomposites is assessed through ageing of films (thickness $\sim 100 \mu \mathrm{m}$ ) at $115^{\circ} \mathrm{C}$, in an air oven, up to $1000 \mathrm{~h}$. It has been shown ${ }^{28}$ that random chain scission reactions associated with the formation of anhydrides, carbonyl and/or carboxyl groups, is the predominant degradation pathway for PLA during thermal- and photo- oxidation (with UV light irradiation at $\lambda>300 \mathrm{~nm}$ ) in the solid state and in presence of oxygen. However, it is 
important to mention that the hydrolytic degradation is considered negligible under the dry conditions used here for thermo-oxidative ageing.

Nevertheless, FTIR spectra (not reported here), of all test samples, acquired at different ageing times during thermo-oxidative degradation until the specimens became brittle and failed, showed no marked change. In particular, the absorption band assigned to anhydride function $\left(1845 \mathrm{~cm}^{-1}\right)$ is not detectable for all samples; moreover, no changes in the carbonyl domain $\left(1700-1800 \mathrm{~cm}^{-1}\right)$ were observed because in this region, all spectra show multiple and high intensity absorption bands related to the chemical structure of PLA.

On the other hand, the ATR-FTIR characterization allows analyses of the chemical changes of surface induced thermo-oxidation of PLA and PLA-based nanocomposites, mainly because the signals in the carbonyl domain appear to be not saturated. In Fig. 8, ATR-FTIR spectra in the range $2000-600 \mathrm{~cm}^{-1}$, normalized using the infrared absorption band at $1453 \mathrm{~cm}^{-1}$ assigned to the asymmetric bending of $\mathrm{CH}_{3}$ group, ${ }^{28}$ of all the samples, collected before and at different ageing times, are shown. It can be seen that the initial (at $0 \mathrm{~h}$ ) signal of the carbonyl band at $1790-1710 \mathrm{~cm}^{-1}$ becomes split up into multiple peaks (see inserts in Fig. 8 a-e) after ageing due to the formation of new carbonyl bonds arising from the degradation processes..$^{28,36-37}$ Moreover, in all the spectra, changes were observed during ageing in the $1400-1000 \mathrm{~cm}^{-1}$ region: the variations of the absorption bands at $1362,1265,1180,1130$ and $1082 \mathrm{~cm}^{-1}$ are related to the change in the vibration modes of $\mathrm{CH}$ and $\mathrm{C}-\mathrm{O}-\mathrm{C}$ groups and the appearance of a new absorption band at $1210 \mathrm{~cm}^{-1}$ suggests the formation of further species bearing $\mathrm{C}=\mathrm{O}$ bonds. ${ }^{36}$ Thermooxidation of all the samples shows also the presence of a new absorption band (around $925 \mathrm{~cm}^{-1}$ ) which is attributed to the presence of $\mathrm{C}=\mathrm{C}$ functional groups in the oxidation products. ${ }^{37}$ However, according to the literature, ${ }^{38}$ the changes observed in the spectra of PLA in between 950 and $920 \mathrm{~cm}^{-1}$, as well as in the $750-650 \mathrm{~cm}^{-1}$ region, are attributable to changes in crystallinity. In addition, an increase of the 
absorption bands in $3700-3500 \mathrm{~cm}^{-1}$ region (not shown here) with degradation time, is mainly related to free hydroxyl groups and $-\mathrm{OH}$ end groups. ${ }^{39}$

The degradation mechanism of PLA is known to occur predominantly by random chain scissions along the polymer backbone, see Fig. 9. ${ }^{28}$ Moreover, the thermal oxidation of PLA-nanocomposites both in the melt ${ }^{40}$ and in the solid state ${ }^{28}$ has been shown to give rise to reduction in the molar mass of the polymer matrix via pathway 1 in Fig. 9. Further, Rasselet et al. ${ }^{28}$ showed that solid state thermal oxidation of PLA results also in a decrease in the $\mathrm{Tg}$ according to the Fox-Flory theory and an increase in crystallinity due to a chemi-crystallization process.

The degradation pathways (2) and (3) would probably occur but the amount of anhydrides species (possibly volatile) would be low and cannot be readily detected.

Assessment of the thermo-oxidative stability of the samples tested can be gained from calorimetric characterization, considering that a reduction of the molecular weight affects thermal properties, also according to literature. ${ }^{41-42}$

To evaluate the extent of changes in $T_{g}$ during thermo-oxidation of PLA and PLA-based nanocomposites samples, thermograms were recorded immediately after quenching scans. Fig. 10 shows the DSC thermograms derived from the second heating scan of neat PLA and PLA-based nanocomposites, and in Table 1, the corresponding $T_{g}, T_{c c}$, melting temperatures $\left(T_{m 1}\right.$ and $\left.T_{m 2}\right)$ and enthalpy of cold crystallization $\left(\Delta H_{\mathrm{cc}}\right)$ and fusion $\left(\Delta H_{m}\right)$ are summarized. The data shown in Table 1 would suggest that all the samples are amorphous, since the absolute values of cold crystallization enthalpy and melting enthalpy are almost the same due to the slow crystallization kinetics of PLA and fast quenching (cooling scan at $\left.40^{\circ} \mathrm{C} / \mathrm{min}\right)$.

It is possible to observe (see Fig. 10) that the thermograms of all the aged samples (from $250 \mathrm{~h}$ to $1000 \mathrm{~h}$ ) show a double melting peak attributed to the melting of the crystalline phases formed during heating, since crystallisation is negligible during the cooling cycle. It is well known ${ }^{43-45}$ that PLA exhibits double 
melting behaviour associated with the stable pseudo-orthorhombic structure melting at the higher temperature ( $\alpha$-form) and the orthorhombic ( $\beta$-form) that melts at a lower temperature. Besides, both $T_{m 1}$ and $T_{m 2}$ of all the samples increased with the thermo-oxidation time, due to the presence of lower molecular weight polymeric chains. Moreover, it is interesting to note that the cold crystallization phenomena occurred also during the second scan and became well pronounced for the thermo-oxidized samples at longer ageing times (see Fig. 10).

The decrease of $\mathrm{T}_{\mathrm{cc}}$ and the increase of $\Delta H_{\mathrm{cc}}$ values (see Table 1) with increasing the thermo-oxidation time for all the samples reveal that a reduction of PLA molar mass makes the systems easier to crystallise. Furthermore, the stabilised systems, i.e. PLA/(AO)OM-Mt and PLA/OM-Mt/AO, exhibit a more limited decrease in $\mathrm{T}_{\mathrm{cc}}$ than the other samples with increased ageing time.

The incorporation of clay does not significantly affect the $T_{g}$ of the nanocomposite when compared to that of the neat matrix (see $\mathrm{T}_{\mathrm{g}}$ values for samples at $\mathrm{t}=\mathrm{Oh}$ ). Further examination of the DSC data shows that the $T_{g}$ shifts towards lower temperatures for the aged samples. Since the lowering of the $T_{g}$ is generally attributed to chain scission processes taking place during oxidation, the $\mathrm{T}_{\mathrm{g}}$ values were plotted as function of the ageing time to help in the evaluation of the thermo-oxidative behaviour of all samples, see Fig. 11. The linear decrease of $\mathrm{T}_{\mathrm{g}}$ observed at the beginning of the thermal treatment $(0-50 \mathrm{~h})$, for all the samples, seems to suggest that chain scission occurs immediately, i.e. with no induction period. The decrease of the $T_{\mathrm{g}}$ values as a function of thermo-oxidation time is more marked for the system PLA/OM-Mt; early decomposition of organo-modifier accelerates the PLA matrix thermal degradation leading to a considerable decrease of the nanocomposite thermo-oxidation resistance. The presence of stabilising molecules, free or chemically linked onto the organo-modifier, increase the thermo-oxidation resistance as can be deduced by analysing the trends of the $T_{\mathrm{g}}$ curves during the first 500 hours. However, the stabiliser which was simply added during mixing, seems to be unable to protect the matrix over longer periods of thermal ageing. 
The much lower extent of decrease in the $T_{g}$ with thermal ageing time observed for the PLA/(AO)OM-Mt nanocomposite sample, Fig. 11, reflects a lower extent of thermo-oxidative degradation (less chain scission) of the polymer.

The beneficial action of the grafted AO functionalities can be related to two main reasons: firstly, the Hoffman elimination reaction which would normally take place in the case of PLA/OM-Mt, see reaction 1

in Fig. 12, would, in the case of PLA/(AO)OM-Mt, no longer catalyze the thermo-oxidative degradation of the polymer due to, most likely, an inadvertent local release of some by-products' with antioxidant function that would be able to help in mitigating the adverse effect of oxidation, see reaction 2 in Fig. 12. Thus, the Hoffman elimination reaction becomes advantageous in that it would produce further stabiliser moieties locally available within the matrix. Secondly, the AO molecules released would be available also to act locally at the interface between the silicate layers and the polymeric macromolecules, which is the critical area for the onset of degradation processes, thus resulting in good overall stabilisation of the PLA-nanocomposites.

\section{CONCLUSIONS}

The control of thermo-oxidative degradation during processing and service lifetime of PLA and PLAbased nanocomposites is a critical issue for their successful large-scale applications.

In this work, a new strategy was adopted to circumvent the issue of thermo-oxidative instability of PLA/clay nanocomposites through the incorporation of antioxidant-containing organo-modifier clay. PLA and its nanocomposites containing commercial $\mathrm{Mt}$ and $\mathrm{OM}-\mathrm{Mt}$, and the novel organo-modified clay (AO)OM-Mt, were prepared by melt processing. The thermal behaviour of these samples, as well as the corresponding nanocomposite samples, prepared conventionally, i.e. by adding separately the AO during processing, were examined by spectroscopic, rheological and calorimetric techniques. The results achieved show that PLA containing (AO)OM-Mt displays better long-term thermo-oxidative stability than all the other nanocomposite samples that lacked the clay-intercalated-AO. The organo-modified clay 
with an in-built thermo-oxidative stability can be thought of as stabilized and stabilizing system, since the Hoffmann reaction is not thought to greatly accelerate the degradation process in the polymer matrix and, more importantly, it could be viewed as a 'relief mechanism' delivering stabilising moieties to the clay platelets/macromolecular interfacial region where degradation would most likely start.

\section{ACKNOWLEDGEMENTS}

This work was financially supported by EU in the field of Marie Curie Action-PEOPLE 2011-IEF, (N:300302), Project: NANOSTAB-GB - Novel Nano-Stabilisation for Green Bioplastic Nanocomposites. Our thanks are also due to $\mathrm{Dr}$ H.H. Sheena for useful discussions and to Prof. C. Gambarotti for the chemical modification of the organo-modifier.

\section{REFERENCES}

1. Mohanty, A.K.; Misra, M.; Drzal, L.Y. J. Polym. Environ. 2002, 10, 19-26.

2. Bordes, P.; Pollet, E.; Avérous, L. Progr. Polym. Sci. 2009, 34, 125-155.

3. Auras, R.; Harte, B.; Selke, S. Macromol. Biosci. 2004, 4, 835-864.

4. Rudnik, E. In Compostable Polymer Materials; Elsevier, 2008; Chapter 9, pp 202-208.

5. Garlotta, D, J. Polym. Environ. 2001, 9, 63-84.

6. LeBaron, P.C.; Wang, Z.; Pinnavaia, T.J. Appl. Clay Sci. 1999, 15, 11-29.

7. Filippi, S.; Dintcheva, N.T.; Scaffaro, R.; La Mantia, F:P.; Polacco, G.; Magagnini, P. Polym. Eng. Sci. 2009, 49, 1187-1197.

8. La Mantia, F.P.; Dintcheva, N.T.; Filippone, G.; Acierno, D. J. Appl. Polym. Sci. 2006, 102, 47494758.

9. Araújo, A.; Botelho, G.; Oliveira, M.; Machado, A.V. Appl. Clay Sci. 2014, 88-89, 144-150.

10. Paul, M.A; Alexandre, M.; Degée, P.; Henrist, C.; Rulmont, A.; Dubois, P. Polymer 2003, 44, 443450.

11. Pluter, M.; Galeski, A.; Alexandre, M.; Paul, M.A.; Dubois, P. J. Appl. Polym. Sci. 2002, 86, 14971506.

12. Balakrishnan, H.; Hassan, A.; Wahit, M.U.; Yussuf, A.A., Razak, S.B.A. Mater. Design. 2010, 31, 3289-3298.

13. Chang, J.H.; An Y.U; Sur G.S. J. Polym. Sci., Part B: Polym. Phys. 2003, 41, 94-103.

14. Ogata, N.; Jimenez, G.; Kawai, H.; Ogihara, T. J. Polym. Sci., Part B: Polym. Phys. 1997, 35, 389396.

15. Wu, D.; Wu, L.; Wu, L; Zhang, M. Polym. Degrad. Stab. 2006, 91, 3149-3155.

16. Picard, E.; Espuche, E.; Fulchiron, R. Appl. Clay Sci. 2011,53, 58-65.

17. Alexandre, M.; Dubois, P. Mater. Sci. Eng. R 2000, 28, 1-63. 
18. Liu, P. Appl. Clay Sci.2007, 38, 64-76.

19. Dintcheva, N.T.; Al-Malaika, S.; La Mantia, F.P. Polym. Degrad. Stab. 2009, 94, 1571-1588.

20. Mailhot, B.; Morlat, S.; Gardette, J.L.; Boucard, S.; Duchet, J.; Gérard, J.F. Polym. Degrad. Stab. 2003, 82, 163-167.

21. Shah, R.K.; Paul, D.R. Polymer 2006, 47, 4075-4084.

22. Botta, L.; Dintcheva, N.T.; La Mantia, F.P. Polym. Degrad. Stab.2009, 94, 712-718.

23. Morlat-Therias, S.; Mailhot, B.; Gardette, J.L.; DaSilva, C.; Haidar, B.; Vidal, A. Polym. Degrad. Stab. 2005, 90, 78-85.

24. Al-Malaika S., Ed. In Reactive Modifiers for Polymers; Blackie Academic \& Professional, London, 1997.

25. Haider, N.; Karlsson, S. Biomacromolecules 2000, 1, 481-487.

26. Fukushima, K.; Abbate, C.; Tabuani, D.; Gennari, M.; Camino, G. Polym. Degrad. Stab. 2009, 94, 1646-1655.

27. Hwang, S.S.; Hsu, P.P.; Yeh, J.M.; Chang, K.C.; Lai, J.Z. Polym. Compos. 2009, 30, 1625-1630.

28. Rasselet, D.; Ruellan, A.; Guinault, A.; Miquelardgarnier, G.; Sollogoub, C.; Fayolle, B. Europ. Polym. J. 2014, 50, 109-116.

29. Dintcheva, N.D.; Al-Malaika, S.; Morici, E. Polym. Degrad. Stab. 2015, 122, 88-101.

30. Wang, H.; Sun, X.Z.; Seib, P. J. Appl. Polym. Sci. 2001, 82, 1761-1767.

31. Madejova' J. Vib. Spectrosc. 2003, 31, 1-10.

32. Saikai, B.J.; Parthasarathy, G. J. Mod. Phys. 2010, 1, 206-210.

33. Filippi, S.; Paci, M.; Polacco, G.; Dintcheva, N.T.; Magagnini, P. Polym. Degrad. Stab. 2011, 96, 823-832.

34. Singh, S, Ghosh, A.K.; Maiti, S.N.; Raha, S.; Gupta, R.K.; Bhattacharya, S. Polym. Eng. Sci. 2012, 52, 225-232.

35. Pluta, M. J. Polym. Sci. Part B Polym. Phys. 2006, 44, 3392-3405.

36. Bocchini,S.; Fukushima, K.; Di Blasio, A.; Fina, A.; Frache, A.; Geobaldo, F. Biomacromol. 2010, 11, 2919-2926.

37. Gardette, M.; Thérias, S.; Gardette, J-L.; Murariu, M.; Dubois, P. Polym. Degrad. Stab. 2011, 96, 616-623.

38. Kister, G.; Cassanas, G.; Vert, M. Polymer 1998, 39, 267-273.

39. Matusik, J.; Stodolak, E.; Bahranowski, K. Appl. Clay Sci. 2011, 51, 102-109.

40. Yanga, L.; Chena, X.; Jing, X. Polym. Degrad. Stab. 2008, 93, 1923-1929.

41. Gorrasi, G.; Pantani, R. Polym. Degrad. Stab. 2013, 98, 1006-1014.

42. Kaynak, C.; Sarı, B. Appl. Clay Sci. 2016, 121-122, 86-94.

43. Yasuniwa, M.; Tsubakihara, S.; Takahashi, K. Polymer 2006, 47, 7554-7563.

44. Mohapatra, A.K.; Mohanty, S.; Nayak, S.L. Polym. Compos. 2012, 33, 2095-2104.

45. Russo, P.; Cammarano, S.; Bilotti, E.; Peijs, T.; Cerruti, P.; Acierno, D. J. Appl. Polym. Sci. 2014, 131, 39798. 
FIGURE 1 Schematic representation of (AO)OM-Mt.

FIGURE 2 FTIR spectra (range from 3800 to $1200 \mathrm{~cm}$-1) of different clays (in $\mathrm{KBr}$ ) along with the deconvoluted peaks for: (AO)OM-Mt(a), and OM-Mt (b).

FIGURE 3 XRD patterns of OM-Mt and (AO)OM-Mt clays.

FIGURE 4 XRD patterns of PLA and PLA based nanocomposite.

FIGURE 5 SEM micrographs of neat PLA (a), PLA/Mt (b), PLA/OM-Mt (c), PLA/(AO)OM-Mt (d) and PLA/OM-Mt/AO (e) at the same magnification.

FIGURE 6 TEM micrographs of PLA/OM-Mt (a) and PLA/(AO)OM-Mt (b) nanocomposites.

FIGURE 7 Complex viscosity curves, $\eta^{*}(a)$, storage modulus, $G^{\prime}(b)$ and loss modulus, G" (c) of neat PLA and PLA-based nanocomposites (measured at $170^{\circ} \mathrm{C}$ ).

FIGURE 8 ATR-FTIR spectra (range 2000 to $600 \mathrm{~cm}-1$ ) of PLA (a), PLA/Mt (b), PLA/OM-Mt (c), PLA/(AO)OM-Mt (d) and PLA/OM-Mt/AO (e) at different ageing times (at $115^{\circ} \mathrm{C}$ ).

FIGURE 9 Possible PLA oxidation mechanism, involving $\beta$-scission of alkoxyl radical ${ }^{22}$.

FIGURE 10 DSC traces at second heating of PLA (a), PLA/Mt (b), PLA/OM-Mt (c), PLA/(AO)OM-Mt (d) and $\mathrm{PLA} / \mathrm{OM}-\mathrm{Mt} / \mathrm{AO}(\mathrm{e})$ at different aging time. Thermograms are recorded at heating rate of $10^{\circ} \mathrm{C} / \mathrm{min}$, after a quenching at $40^{\circ} \mathrm{C} / \mathrm{min}$.

FIGURE $11 \mathrm{Tg}$ values as function of the thermo-oxidation time for neat PLA and PLA-based nanocomposites.

FIGURE 12 Hoffman elimination reaction (1) and mechanism of AO functionalities release (2). 
TABLE 1 Thermal properties evaluated from the second heating scan of PLA and its nanocomposites, at different oxidation time

\begin{tabular}{|c|c|c|c|c|c|c|c|}
\hline $\begin{array}{l}\text { Sample } \\
\text { ID }\end{array}$ & $\begin{array}{l}T_{g} \\
\left({ }^{\circ} \mathrm{C}\right)\end{array}$ & $\begin{array}{l}T_{\mathrm{cc}} \\
\left({ }^{\circ} \mathrm{C}\right)\end{array}$ & $\begin{array}{l}-\Delta H_{\mathrm{cc}} \\
(\mathrm{J} / \mathrm{g})\end{array}$ & $\begin{array}{l}T_{m 1} \\
\left({ }^{\circ} \mathrm{C}\right)\end{array}$ & $\begin{array}{l}T_{m 2} \\
\left({ }^{\circ} \mathrm{C}\right)\end{array}$ & $\begin{array}{l}\Delta H m \\
(\mathrm{~J} / \mathrm{g})\end{array}$ & $\begin{array}{l}X_{c} \\
(\%)\end{array}$ \\
\hline \multicolumn{8}{|l|}{ PLA } \\
\hline Oh & $58.5 \pm 0.4$ & $126.5^{(* *)}$ & $9.3 \pm 0.5$ & - & $151.0 \pm 0.3$ & $9.3 \pm 0.5$ & $\mathrm{a}^{(*)}$ \\
\hline $50 \mathrm{~h}$ & $57.8 \pm 0.4$ & $126.5^{(* *)}$ & $5.5 \pm 0.5$ & - & $151.8 \pm 0.3$ & $5.9 \pm 0.4$ & $\mathrm{a}^{(*)}$ \\
\hline $250 \mathrm{~h}$ & $55.1 \pm 0.4$ & $106.2 \pm 0.4$ & $39.5 \pm 1.1$ & $142.7 \pm 0.3$ & $151.0 \pm 0.4$ & $40.5 \pm 1.2$ & $\mathrm{a}^{(*)}$ \\
\hline $500 \mathrm{~h}$ & $52.5 \pm 0.6$ & $102.0 \pm 0.5$ & $45.3 \pm 1.5$ & $143.5 \pm 0.3$ & $152.0 \pm 0.4$ & $45.8 \pm 1.4$ & $a^{(*)}$ \\
\hline $750 \mathrm{~h}$ & $52.2 \pm 0.3$ & $101.5 \pm 0.3$ & $42.0 \pm 1.3$ & $145.0 \pm 0.4$ & $152.8 \pm 0.4$ & $43.0 \pm 1.3$ & $a^{(*)}$ \\
\hline $1000 \mathrm{~h}$ & $52.0 \pm 0.3$ & $99.0 \pm 0.4$ & $42.5 \pm 1.3$ & $145.6 \pm 0.4$ & $153.5 \pm 0.4$ & $42.8 \pm 1.2$ & $\mathrm{a}^{(*)}$ \\
\hline \multicolumn{8}{|l|}{$P L A / M t$} \\
\hline $\mathrm{Oh}$ & $58.9 \pm 0.4$ & $123.5^{(* *)}$ & $27.2 \pm 0.9$ & - & $151.8 \pm 0.3$ & $27.6 \pm 0.8$ & $\mathrm{a}^{(*)}$ \\
\hline $50 \mathrm{~h}$ & $57.6 \pm 0.4$ & $124.5^{(\star *)}$ & $15.3 \pm 0.5$ & - & $151.0 \pm 0.3$ & $15.9 \pm 0.5$ & $\mathrm{a}^{(*)}$ \\
\hline $250 \mathrm{~h}$ & $55.3 \pm 0.5$ & $102.2 \pm 0.4$ & $36.7 \pm 1.0$ & - & $152.0 \pm 0.4$ & $37.2 \pm 1.1$ & $\mathrm{a}^{(*)}$ \\
\hline $500 \mathrm{~h}$ & $53.0 \pm 0.5$ & $100.0 \pm 0.5$ & $40.2 \pm 1.2$ & $146.5 \pm 0.4$ & $152.7 \pm 0.4$ & $40.7 \pm 1.1$ & $a^{(*)}$ \\
\hline $750 \mathrm{~h}$ & $52.7 \pm 0.5$ & $97.0 \pm 0.4$ & $41.5 \pm 1.2$ & $146.8 \pm 0.4$ & $153.0 \pm 0.3$ & $42.1 \pm 1.2$ & $\mathrm{a}^{(*)}$ \\
\hline $1000 \mathrm{~h}$ & $52.6 \pm 0.5$ & $95.5 \pm 0.3$ & $42.1 \pm 1.2$ & $147.0 \pm 0.4$ & $153.5 \pm 0.3$ & $42.9 \pm 1.2$ & $\mathrm{a}^{(*)}$ \\
\hline \multicolumn{8}{|c|}{ PLA/OM-Mt } \\
\hline Oh & $58.7 \pm 0.5$ & $125.0^{(* *)}$ & $11.8 \pm 0.3$ & - & $151.0 \pm 0.3$ & $12.5 \pm 0.4$ & $\mathrm{a}^{(*)}$ \\
\hline $50 \mathrm{~h}$ & $57.5 \pm 0.4$ & $125.0^{(* *)}$ & $5.4 \pm 0.2$ & - & $151.0 \pm 0.4$ & $6.2 \pm 0.2$ & $a^{(*)}$ \\
\hline $250 \mathrm{~h}$ & $54.8 \pm 0.4$ & $103.8 \pm 0.4$ & $33.2 \pm 1.0$ & $143.9 \pm 0.4$ & $151.7 \pm 0.3$ & $34.0 \pm 1.2$ & $\mathrm{a}^{(*)}$ \\
\hline $500 \mathrm{~h}$ & $51.6 \pm 0.3$ & $100.5 \pm 0.4$ & $36.7 \pm 1.1$ & $147.0 \pm 0.4$ & $153.5 \pm 0.4$ & $36.8 \pm 1.2$ & $a^{(*)}$ \\
\hline $750 \mathrm{~h}$ & $51.0 \pm 0.4$ & $98.0 \pm 0.5$ & $37.5 \pm 1.2$ & $146.8 \pm 0.4$ & $153.7 \pm 0.4$ & $38.0 \pm 1.3$ & $\mathrm{a}^{(*)}$ \\
\hline $1000 \mathrm{~h}$ & $50.5 \pm 0.4$ & $96.0 \pm 0.5$ & $38.5 \pm 1.3$ & $148.0 \pm 0.4$ & $153.7 \pm 0.5$ & $38.7 \pm 1.3$ & $a^{(*)}$ \\
\hline \multicolumn{8}{|c|}{$P L A /(A O) O M-M t$} \\
\hline $\mathrm{Oh}$ & $58.8 \pm 0.4$ & $127.5^{(*)}$ & $15.4 \pm 0.4$ & - & $151.5 \pm 0.4$ & $15.8 \pm 0.5$ & $a^{(*)}$ \\
\hline $50 \mathrm{~h}$ & $58.0 \pm 0.3$ & $127.5^{(\star *)}$ & $8.5 \pm 0.2$ & - & $151.0 \pm 0.4$ & $9.2 \pm 0.4$ & $\mathrm{a}^{(*)}$ \\
\hline $250 \mathrm{~h}$ & $56.2 \pm 0.3$ & $109.8 \pm 0.4$ & $33.3 \pm 1.0$ & $142.8 \pm 0.3$ & $151.0 \pm 0.4$ & $34.0 \pm 1.1$ & $\mathrm{a}^{(*)}$ \\
\hline $500 \mathrm{~h}$ & $54.1 \pm 0.4$ & $108.0 \pm 0.3$ & $37.1 \pm 1.3$ & $144.5 \pm 0.3$ & $152.0 \pm 0.3$ & $37.8 \pm 1.2$ & $\mathrm{a}^{(*)}$ \\
\hline $750 \mathrm{~h}$ & $53.9 \pm 0.4$ & $103.0 \pm 0.3$ & $36.2 \pm 1.3$ & $145.0 \pm 0.3$ & $152.0 \pm 0.3$ & $36.5 \pm 1.3$ & $a^{(*)}$ \\
\hline $1000 \mathrm{~h}$ & $53.8 \pm 0.4$ & $103.0 \pm 0.4$ & $38.8 \pm 1.4$ & $145.5 \pm 0.3$ & $154.0 \pm 0.3$ & $39.3 \pm 1.5$ & $a^{(*)}$ \\
\hline \multicolumn{8}{|c|}{ PLA/OM-Mt/AO } \\
\hline $\mathrm{Oh}$ & $58.0 \pm 0.3$ & $129.0^{(*)}$ & $1.2 \pm 0.1$ & - & $150.0 \pm 0.4$ & $1.8 \pm 0.1$ & $a^{(*)}$ \\
\hline $50 \mathrm{~h}$ & $57.0 \pm 0.4$ & $126.0^{(* *)}$ & $3.3 \pm 0.2$ & - & $150.0 \pm 0.4$ & $4.1 \pm 0.2$ & $\mathrm{a}^{(*)}$ \\
\hline $250 \mathrm{~h}$ & $54.8 \pm 0.4$ & $111.8 \pm 0.4$ & $38.3 \pm 1.4$ & $144.7 \pm 0.3$ & $151.0 \pm 0.4$ & $38.5 \pm 1.4$ & $a^{(*)}$ \\
\hline $500 \mathrm{~h}$ & $52.3 \pm 0.3$ & $109.0 \pm 0.3$ & $38.1 \pm 1.5$ & $145.8 \pm 0.4$ & $151.8 \pm 0.3$ & $38.6 \pm 1.3$ & $\mathrm{a}^{(*)}$ \\
\hline $750 \mathrm{~h}$ & $51.9 \pm 0.3$ & $105.2 \pm 0.3$ & $41.6 \pm 1.3$ & $146.2 \pm 0.4$ & $152.8 \pm 0.3$ & $42.0 \pm 1.5$ & $a^{(*)}$ \\
\hline $1000 \mathrm{~h}$ & $51.0 \pm 0.3$ & $103.0 \pm 0.4$ & $42.0 \pm 1.3$ & $147.5 \pm 0.3$ & $153.8 \pm 0.4$ & $42.4 \pm 1.5$ & $\mathrm{a}^{(*)}$ \\
\hline
\end{tabular}

Note: $\left({ }^{*}\right) \mathrm{a}=$ amorphous; calculated crystallinity degree is about zero, i.e. less than $1 \%$.

$\left({ }^{\star *}\right)$ not well detectable 